\title{
What are the similarities and differences in structure and function among the three main models of community health centers in China: a systematic review
}

\author{
Haitao $\mathrm{Li}^{1 \dagger}$, Dongfu Qian ${ }^{2 \dagger}$, Sian Griffiths ${ }^{3}$, Roger Yat-nork Chung ${ }^{3}$ and Xiaolin Wei $\mathrm{i}^{3,4^{*}}$
}

\begin{abstract}
Background: There are three major models of primary care providers (Community Health Centers, CHCs) in China, i.e., government managed, hospital managed and privately owned CHCs. We performed a systematic review of structures and health care delivery patterns of the three models of CHCs.

Methods: Studies from relevant English and Chinese databases for the period of 1997-2011 were searched. Two independent researchers extracted data from the eligible studies using a standardized abstraction form. Methodological quality of included articles was assessed with the Mixed Methods Appraisal Tool (MMAT).

Results: A total of 13 studies was included in the final analysis. Compared with the other two models, private CHCs had a smaller health workforce and lower share of government funding in their total revenues. Private CHCs also had fewer training opportunities, were less recognized by health insurance schemes and tended to provide primary care services of poor quality. Hospital managed CHCs attracted patients through their higher quality of clinical care, while private $\mathrm{CHCs}$ attracted users through convenience and medical equipment.

Conclusions: Our study suggested that government and hospital managed CHCs were more competent and provided better primary care than privately owned CHCs. Further studies are warranted to comprehensively compare performances among different models of CHCs.
\end{abstract}

Keywords: Primary care, Community health service, Community health center, Model, Systematic review

\section{Background}

The greatest discontents reflected by the public in China are the difficult access to health care, and impoverishment due to heavy medical expenses, which are commonly known respectively in Chinese as "Kan bing nan, and "Kan bing gui" [1]. It has been shown that over one third of households have reduced their consumption or been impoverished by health-related expenditures in China [1]. In addition, significant inequalities exist in health care utilization and health care outcomes across

\footnotetext{
* Correspondence: xiaolinwei@cuhk.edu.hk

${ }^{\dagger}$ Equal contributors

${ }^{3}$ School of Public Health and Primary Care, Faculty of Medicine, The Chinese University of Hong Kong, Hong Kong, China

${ }^{4}$ Dalla Lana School of Public Health, University of Toronto, Toronto, Canada Full list of author information is available at the end of the article
}

regions, between rural and urban areas, and across populations with different socioeconomic statuses $[2,3]$. Primary care is widely considered to be the cornerstone of a health system, since it brings improved access to essential health services, puts heavier focus on prevention and initiates early management of health problems, which lead to better health outcomes and less health inequity in the population [4-9]. In 2009, China launched its comprehensive health reform plan aiming to build a more equitable and efficient health system through a stronger primary care system [10].

Primary care in China is mainly provided by Community Health Centers (CHCs) in urban areas and township hospitals in rural areas. Due to the rapid urbanization, most township hospitals were also called $\mathrm{CHCs}$ in order to respond the rapidly rising health needs in emerging 
towns. CHCs were firstly established by government or public hospitals in 1997. In 1999, government began to promote privately owned $\mathrm{CHCs}$ due to the inadequate public funding. Since then, there has been a rapid expansion in the number of $\mathrm{CHCs}$ in China. The proportion of cities with $\mathrm{CHCs}$ offering primary care to the public reached over $90 \%$ in 2009 with a total number of 27,308 $\mathrm{CHCs}$ [11]. There are three major models of $\mathrm{CHCs}$ in terms of ownership and operation, i.e., government managed, hospital managed, and privately owned CHCs [12]. Government managed and hospital managed $\mathrm{CHCs}$ accounted for the majority of all CHCs (77\% in 2007) [13], while privately owned CHCs accounted for $9 \%$ and were mainly located in the western and southern parts of China [13].

Government managed $\mathrm{CHCs}$ are independent entities fully funded and directly supervised by the local governments. The governments thus assume greater responsibilities in supporting and promoting $\mathrm{CHCs}^{\prime}$ development. In addition, these $\mathrm{CHCs}$ are independent of public hospitals. The majority of $\mathrm{CHCs}$ with this model were converted either from former first-level hospitals or from the outreach clinics of secondary and tertiary hospitals. Their functions were transformed from providing clinically focused services to providing combined and integrated primary care services, which included clinical care, preventive medical care, health education and promotion, rehabilitation, technical support for family planning, as well as chronic disease management.

Hospital managed CHCs are established directly by a hosting public hospital. Since public hospitals are owned by the government, $\mathrm{CHCs}$ of this model are indirectly owned by governments, but directly operated and managed by the hosting hospitals as non-independent entities, often as a department or an out-reach clinic. Hosting hospitals play an essential role in financing, managing and supervising of these CHCs. For example, government funding is allocated to the $\mathrm{CHCs}$ via their hosting hospitals.

Privately owned $\mathrm{CHCs}$ are private businesses who take full responsibility for profits and losses. They receive partial financial support from the government for the provision of public health services for the relatively permanent populations in the catchment area. Similar to government managed ones, private $\mathrm{CHCs}$ are also independent of public hospitals.

The different ownership types of $\mathrm{CHCs}$ determine to whom and for what they are held accountable, which would consequently influence the delivery of community health services (i.e., the delivery of primary care services), and in turn, the health status and satisfaction of the populations being served [14]. In recent years, there has been a lively debate regarding the preferred primary care model as a regular source of care for solving the problem of inefficient use of medical resources. However, there has been limited evidence in China or elsewhere concerning the impact of these ownership types on delivery by different primary care providers. We therefore performed this systematic review to identify the differences among the three models of $\mathrm{CHCs}$ in terms of their structure and primary care service delivery, to show relative attributes and benefits of different models of CHCs, which was expected to provide valuable feedback to policy makers for establishing a better primary care-led healthcare system in China and similar settings.

\section{Methods}

We conducted a systematic review according to the following strategies. The Preferred Items for Systematic Reviews and Meta-Analyses (PRISMA) guidelines were followed to report the review process.

\section{Search criteria}

We retrieved literature from the English databases of MEDLINE and EMBASE, and the Chinese databases of CNKI, VIP and WANFANG, which were published from January 1997 to September 2011. We chose the year 1997 as the starting year because it was the time when the community health service system was established in China. The searching terms included "Community Health Service", "Community Health Center", "Community Health Station", "Community Health Organization", "primary care" or "primary health care" and a search for "ownership", "source", "model", "type", "government", "hospital" or "private". The specific search strategy was shown in Table 1. References listed in published articles such as literature reviews were screened to identify additional sources not identified in the database searches.

\section{Study selection criteria \\ Language and location}

Only papers published in Chinese or English were included in the study. We confined the country to China

Table 1 Search terms and search strategy

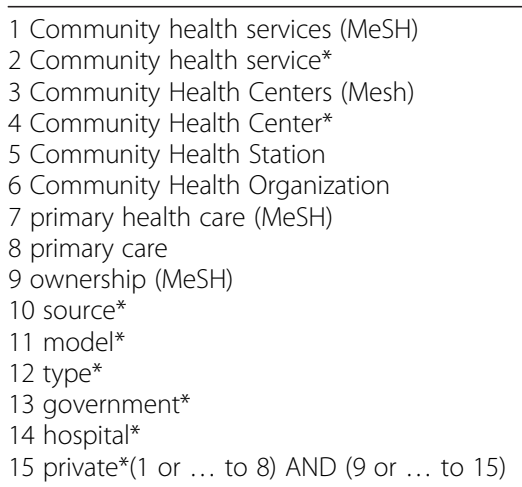

*Treated as a placeholder for any unknown term(s) 
only, but the study location was not restricted, meaning that the study could be at a national or district level.

\section{Study designs}

We included both cross-sectional and longitudinal studies. Literature reviews in research papers were also included. Articles such as opinion pieces, letters, news, commentaries, editorial, meeting abstracts and bibliographies were excluded as no research evidence was provided.

\section{Target of studies}

We looked for literature that investigated differences among the three models of CHCs, i.e., government managed, hospital managed or privately owned CHCs. The comparison could be among all of the three models, between any two of them, between a combination of any two with the other, or among primary, secondary and tertiary hospital managed CHCs.

\section{Selection of publications}

Two reviewers independently evaluated the relevance of each article by considering the title and abstract. Subsequently, the full texts of the papers identified as potentially relevant were obtained. If we were uncertain whether or not the paper qualified for inclusion, we nonetheless included it and obtained the full text. Uncertainties were then resolved by discussion between the two reviewers. According to the eligibility criteria, we then screened all the full texts to select the relevant studies.

\section{Data extraction}

A standardized data extraction form was formulated by the research team. Two researchers independently performed data extraction. One researcher was responsible for the initial data extraction, while the other was in charge of verifying the data extracted by the first researcher. The information extracted from the selected studies included main authors, study design, time period of data, data sources and contents of the study. To frame the analysis, any of the following issues of $\mathrm{CHCs}$ that were addressed by the included papers were extracted: 1 ) structure, which referred to a collection of organizational factors of $\mathrm{CHCs}$ that defined how the primary care services were provided, including human resources, financing aspects and premises; 2) delivery of primary care services including community health service utilization and quality; and 3) outcome measured by public satisfaction.

\section{Quality assessment}

All included articles were independently assessed for methodological quality by the two reviewers. We used adapted Mixed Methods Appraisal Tool (MMAT) for quality assessment [15]. This tool was judged suitable to be used in mixed method reviews, being with substantial validity and reliability. The MMAT used in our study contained three sets of criteria: 1) a "qualitative" set for qualitative studies, and qualitative components of mixed methods research; 2) an "observational descriptive" set for observational descriptive quantitative studies, and observational descriptive components of mixed methods research; and 3) a "mixed methods" set for mixed methods research studies. Each study type was judged within its methodological domain. For each criterion, the presence/ absence was scored 1 and 0, respectively [16]. Discrepancies in quality assessment between reviewers related primarily to how findings related to researchers' influence and sampling strategy of quantitative data, and were settled through consensus. A quality score for each article was then calculated through dividing the total points scored by the total points possible. Each article was classified as weak $(\leq 0.50)$, moderate-weak $(0.51$ to 0.65$)$, moderate-strong $(0.66$ to 0.79$)$, or strong $(\geq 0.80)$ in terms of study quality [17].

\section{Results}

The initial search yielded 536 papers. Following the selection process as shown in Fig. 1, we first excluded 431 articles after reviewing titles and abstracts, which arrived at 105 articles with full texts. Among these 105 articles, 13 met the inclusion criteria and formed the basis of the findings. All the 13 articles were of cross-sectional study design and were in Chinese, among which 6 were conducted at the national level and the others were at either the provincial or municipal level. Of all the 13 included papers, five studies compared among the three models of CHCs, five compared combined government managed and hospital managed $\mathrm{CHCs}$ with privately owned $\mathrm{CHCs}$, and three compared among primary, secondary and tertiary hospital managed CHCs (Table 2).

Table 3 shows the methodological quality of the included articles. Of the included reports, 5 were rated as strong, 7 as moderate-strong, and 1 as moderate-weak, respectively. The validity and reliability of research measures used were not reported or were "assumed" to be valid and reliable based on their own subjective judgment in the majority of these articles. Nonetheless, they were widely recognized as effective measures (Table 3 ).

\section{Structure}

We identified differences in operation structure on the aspects of financing, premises and human resources.

\section{Financing}

The revenues of CHCs in China came from three major sources: government funding, health insurance reimbursement, and out-of-pocket payments from patients. 


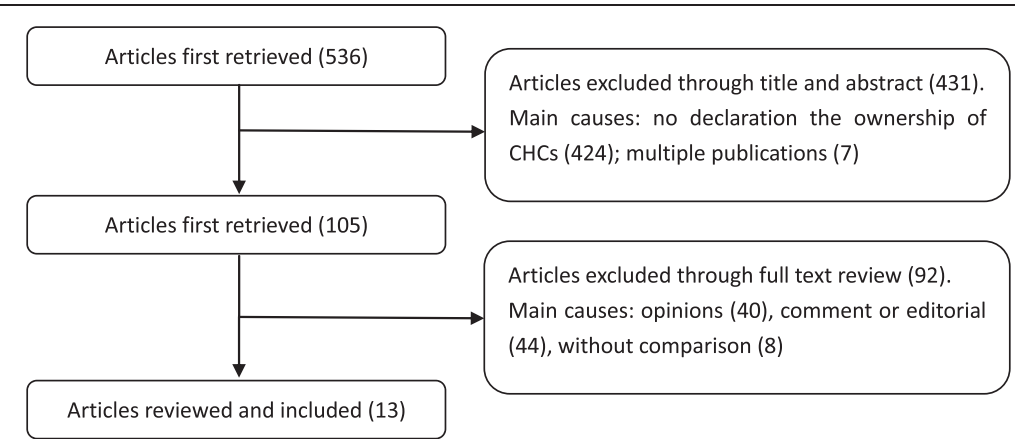

Fig. 1 Shows the study selection process. Of the initially yielded 536 papers, we firstly excluded 431 ones by reviewing titles and abstracts, arriving at 105 articles with full texts. Among the 105 articles, 13 met the inclusion criteria and formed the basis of the findings. All the 13 articles were of cross-sectional study design and were in Chinese

Overall, three studies focused on the financing of the different models of CHCs [13, 18, 19].

Two studies provided information regarding the proportion of government funding in total $\mathrm{CHC}$ revenue $[13,18]$. Both studies showed that government funding accounted for a higher proportion in government managed and hospital managed $\mathrm{CHCs}$ than privately owned CHCs. One study in 29 cities across China pointed out that in 2007 government funding accounted for less than $7 \%$ of the total revenue of privately owned $\mathrm{CHCs}$, while the proportion was $19 \%$ for that of the other two models [13]. Another study conducted in Harbin city of the Heilongjiang Province showed that government funding accounted for $25 \%$ of total revenues in government and hospital managed $\mathrm{CHCs}$, but privately owned $\mathrm{CHCs}$ did not receive any government funding at all [18].
Two studies described whether services in $\mathrm{CHCs}$ had been covered by health insurance schemes [13, 19]. Along with the rapid expansion of health insurance schemes including the Basic Medical Insurance for Urban Employees and the Basic Medical Insurance for Urban Residents, more $\mathrm{CHCs}$ had been covered by health insurance schemes over time [20]. The study in 29 cities of China showed that $34 \%$ of privately owned $\mathrm{CHCs}$ and $43 \%$ of government and hospital managed $\mathrm{CHCs}$ were covered by insurance schemes [13]. Another study found the coverage rate was $62 \%$ for privately owned CHCs, $66 \%$ for government managed CHCs and $79 \%$ for hospital managed CHCs [19].

Nevertheless, government funding and health insurance reimbursement were insufficient to support running $\mathrm{CHCs}$ in all the three models. Patients' out-of-pocket

Table 2 Characteristics of the included studies

\begin{tabular}{|c|c|c|c|c|c|c|c|}
\hline \multirow[t]{2}{*}{ Main author } & \multirow[t]{2}{*}{ Comparison } & \multirow[t]{2}{*}{ Study area } & \multirow[t]{2}{*}{ Study design } & \multirow[t]{2}{*}{ Data sources } & \multicolumn{3}{|c|}{ Contents of the study } \\
\hline & & & & & Structure & $\begin{array}{l}\text { Delivery of health } \\
\text { services }\end{array}$ & $\begin{array}{l}\text { Public } \\
\text { satisfaction }\end{array}$ \\
\hline Zhao et al. (2010) [26] & G vs. H vs. P & National & Cross sectional & Survey and interview & $\sqrt{ }$ & $\sqrt{ }$ & $\sqrt{ }$ \\
\hline Wang (2008) [13] & $G+H$ vs. $P$ & National & Cross sectional & Survey and interview & $\sqrt{ }$ & $\sqrt{ }$ & \\
\hline Guo (2010) [21] & G vs. H vs. P & Guangdong province & Cross sectional & Survey and interview & $\sqrt{ }$ & $\sqrt{ }$ & $\sqrt{ }$ \\
\hline Zhang (2008) [23] & G vs. H vs. P & Jiangsu province & Cross sectional & Survey and interview & $\sqrt{ }$ & & \\
\hline Li (2009) [30] & $\mathrm{H} 1$ vs. $\mathrm{H} 2$ & Shenzhen & Cross sectional & Survey and interview & $\sqrt{ }$ & & \\
\hline Fan et al. (2007) [18] & $G+H$ vs. P & Heilongjiang & Cross sectional & Survey & $\sqrt{ }$ & & \\
\hline Yao et al. (2010) [27] & G vs. H vs. P & National & Cross sectional & Survey and interview & & & $\sqrt{ }$ \\
\hline Li et al. (2010) [25] & $G+H$ vs. $P$ & National & Cross sectional & Survey & $\sqrt{ }$ & & $\sqrt{ }$ \\
\hline Yang \& Dai (2010) [22] & $G+H$ vs. $P$ & Chengdu City & Cross sectional & Survey & $\sqrt{ }$ & $\sqrt{ }$ & \\
\hline Chen \& Du (2010) [24] & H1vs. $\mathrm{H} 2$ vs. $\mathrm{H} 3$ & Beijing City & Cross sectional & Survey & $\sqrt{ }$ & $\sqrt{ }$ & \\
\hline Wang et al. (2009) [28] & $G+H$ vs. $P$ & National & Cross sectional & Survey & & & $\sqrt{ }$ \\
\hline Xu et al. (2011) [19] & G vs. H vs. P & National & Cross sectional & Survey & $\sqrt{ }$ & $\sqrt{ }$ & \\
\hline Chen et al. (2009) [29] & H1vs. H2 vs. H3 & Beijing City & Cross sectional & Survey & & & $\sqrt{ }$ \\
\hline
\end{tabular}


Table 3 Quality assessment of the included studies using Mixed Methods Appraisal Tool (MMAT)

\begin{tabular}{|c|c|c|c|c|c|c|c|c|c|c|c|c|c|c|}
\hline \multirow{2}{*}{$\begin{array}{l}\text { Author(s), } \\
\text { Year }\end{array}$} & \multicolumn{4}{|l|}{ Qualitative } & \multicolumn{4}{|c|}{ Quantitative descriptive } & \multicolumn{3}{|l|}{ Mixed methods } & \multirow{2}{*}{$\begin{array}{l}\text { Total } \\
\text { Points }\end{array}$} & \multirow{2}{*}{ Score } & \multirow[t]{2}{*}{ Quality } \\
\hline & $\begin{array}{l}\text { Sources of } \\
\text { data relevant } \\
\text { to objectives }\end{array}$ & $\begin{array}{l}\text { Analysis } \\
\text { process } \\
\text { relevant to } \\
\text { objectives }\end{array}$ & $\begin{array}{l}\text { Consideration } \\
\text { of findings } \\
\text { relate to } \\
\text { context }\end{array}$ & $\begin{array}{l}\text { Consideration of } \\
\text { findings relate } \\
\text { to researchers' } \\
\text { influence }\end{array}$ & $\begin{array}{l}\text { Sampling } \\
\text { strategy } \\
\text { relevant to } \\
\text { objectives }\end{array}$ & $\begin{array}{l}\text { Sample } \\
\text { representativeness }\end{array}$ & $\begin{array}{l}\text { Measurements } \\
\text { appropriate }\end{array}$ & $\begin{array}{l}\text { Acceptable } \\
\text { response } \\
\text { rate }\end{array}$ & $\begin{array}{l}\text { Mixed methods } \\
\text { research design } \\
\text { relevant to } \\
\text { objectives }\end{array}$ & $\begin{array}{l}\text { Integration } \\
\text { of results } \\
\text { relevant to } \\
\text { objectives }\end{array}$ & $\begin{array}{l}\text { Consideration } \\
\text { of limitations } \\
\text { associated with } \\
\text { this integration }\end{array}$ & & & \\
\hline $\begin{array}{l}\text { Zhao et al. } \\
\text { (2010) [26] }\end{array}$ & 1 & 1 & 1 & 0 & 1 & 1 & 1 & 1 & 1 & 0 & 0 & $8 / 11$ & 0.73 & Moderate-Strong \\
\hline $\begin{array}{l}\text { Wang } \\
\text { (2008) [13] }\end{array}$ & 1 & 1 & 1 & 0 & 1 & 1 & 1 & 1 & 1 & 0 & 0 & $8 / 11$ & 0.73 & Moderate-Strong \\
\hline $\begin{array}{l}\text { Guo } \\
\text { (2010) [21] }\end{array}$ & 1 & 1 & 1 & 0 & 1 & 1 & 1 & 1 & 1 & 0 & 0 & $8 / 11$ & 0.73 & Moderate-Strong \\
\hline $\begin{array}{l}\text { Zhang } \\
\text { (2008) [23] }\end{array}$ & 1 & 1 & 1 & 0 & 1 & 0 & 1 & 1 & 1 & 0 & 0 & $7 / 11$ & 0.64 & Moderate-Weak \\
\hline $\begin{array}{l}\text { Li (2009) } \\
\text { [30] }\end{array}$ & 1 & 1 & 1 & 0 & 1 & 1 & 1 & 1 & 1 & 0 & 0 & $8 / 11$ & 0.73 & Moderate-Strong \\
\hline $\begin{array}{l}\text { Fan et al. } \\
\text { (2007) [18] }\end{array}$ & N/A & N/A & N/A & $\mathrm{N} / \mathrm{A}$ & 1 & 1 & 1 & 1 & N/A & N/A & N/A & $4 / 4$ & 1.00 & Strong \\
\hline $\begin{array}{l}\text { Yao et al. } \\
\text { (2010) [27] }\end{array}$ & 1 & 1 & 1 & 0 & 1 & 1 & 1 & 1 & 1 & 0 & 0 & $8 / 11$ & 0.73 & Moderate-Strong \\
\hline $\begin{array}{l}\text { Li et al. } \\
\text { (2010) [25] }\end{array}$ & N/A & N/A & N/A & N/A & 1 & 1 & 1 & 1 & N/A & N/A & N/A & $4 / 4$ & 1.00 & Strong \\
\hline $\begin{array}{l}\text { Yang \& Dai } \\
\text { (2010) [22] }\end{array}$ & $\mathrm{N} / \mathrm{A}$ & $\mathrm{N} / \mathrm{A}$ & N/A & $\mathrm{N} / \mathrm{A}$ & 1 & 1 & 1 & 1 & N/A & N/A & N/A & $4 / 4$ & 1.00 & Strong \\
\hline $\begin{array}{l}\text { Chen \& Du } \\
\text { (2010) [24] }\end{array}$ & N/A & N/A & N/A & $\mathrm{N} / \mathrm{A}$ & 1 & 0 & 1 & 1 & N/A & N/A & $\mathrm{N} / \mathrm{A}$ & $3 / 4$ & 0.75 & Moderate-Strong \\
\hline $\begin{array}{l}\text { Wang et al. } \\
\text { (2009) [28] }\end{array}$ & N/A & N/A & N/A & N/A & 1 & 1 & 1 & 1 & N/A & N/A & N/A & $4 / 4$ & 1.00 & Strong \\
\hline $\begin{array}{l}\text { Xu et al. } \\
\text { (2011) [19] }\end{array}$ & N/A & N/A & N/A & $\mathrm{N} / \mathrm{A}$ & 1 & 1 & 1 & 1 & N/A & N/A & $\mathrm{N} / \mathrm{A}$ & $4 / 4$ & 1.00 & Strong \\
\hline $\begin{array}{l}\text { Chen et al. } \\
\text { (2009) [29] }\end{array}$ & N/A & N/A & N/A & N/A & 1 & 0 & 1 & 1 & N/A & N/A & N/A & $3 / 4$ & 0.75 & Moderate-Strong \\
\hline
\end{tabular}


payments for medical services and drugs remained the major source of revenue for CHCs. The share of out-ofpocket payments accounted for $57 \%$ in privately owned $\mathrm{CHCs}$, and $51 \%$ in the other two models of $\mathrm{CHCs}$ [13].

\section{Premises}

Four studies described premises in different models of CHCs $[13,18,21,22]$. Two studies found that privately owned $\mathrm{CHCs}$ tended to rent their offices while the other models of CHCs tended to own their own offices [13, 21]. A study in Guangdong province showed that nearly $97 \%$ of the offices of privately owned $\mathrm{CHCs}$ were rented in 2009, while the percentages were 57 and $22 \%$ for hospital managed and government managed $\mathrm{CHCs}$, respectively [21]. Wang's study found that $77 \%$ of the offices in the private CHCs were rented in 2007 which was higher than that of the other two models of CHCs [13].

Regarding the building area of $\mathrm{CHC}$ offices, we did not draw a conclusion from the four included studies. Of the four studies, two showed that the building area of privately owned $\mathrm{CHCs}$ was larger than that of the other two models of CHCs $[13,18]$, while the other two studies showed opposite results [21, 22].

\section{Human resources}

Overall, seven studies addressed the human resources of the different models of CHCs [13, 18, 21-25]. The CHC workforce has expanded rapidly during the last decade. The number of doctors increased from 17,281 in 2003 to 109,734 in 2009 , and the number of nurses grew from 12,484 to 79,711 during the same period [12]. Privately owned CHCs employed fewer health workers compared to the other two models of CHCs [13, 22]. Moreover, fewer training opportunities of primary care were provided to doctors and nurses working at privately owned $\mathrm{CHCs}$ than those working at the other two models of CHCs [13].

The education level of the entire health workforce among the three models of $\mathrm{CHCs}$ remained low compared to that in hospitals. Most of doctors and nurses in $\mathrm{CHCs}$ had only received 3-year medical training from medical colleges, or equivalent training from secondary schools, while most doctors in hospitals had a 5 year bachelor degree from medical universities. We did not draw any conclusion from the six studies regarding the differences in the education level of health workers among the different models of CHCs (Table 4). Three studies indicated that the general education level of health workers in privately owned $\mathrm{CHCs}$ was lower than that in the other two models of CHCs [21-23]. The study in Guangdong province showed that about $61 \%$ of the health workforce graduated from technical secondary school, as compared to about one third in the other two models of CHCs [21]. Most health workers in privately owned $\mathrm{CHCs}$ in Chengdu had only reached a secondary school education level, while about one third in government managed and hospital managed $\mathrm{CHCs}$ had college education levels [22]. The proportion of health workers with an undergraduate education level in privately owned $\mathrm{CHCs}$ in Jiangsu province and Chengdu city was lower than the other two models of CHCs [23]. However, the study by $\mathrm{Li}$ and colleagues [25] at a

Table 4 The percentage of health workers with different education level and professional title

\begin{tabular}{|c|c|c|c|c|c|c|c|}
\hline \multirow[t]{2}{*}{ First author } & \multirow[t]{2}{*}{ Comparison } & \multicolumn{3}{|l|}{ Education level } & \multicolumn{3}{|c|}{ Professional title } \\
\hline & & $>5$-yearundergraduate & 3-year college & $<$ technical secondary school & Senior & Middle & Junior \\
\hline \multirow[t]{3}{*}{ Guo Haixiu } & G & 16.1 & 48.0 & 30.3 & 0.2 & 8.6 & 62.2 \\
\hline & $\mathrm{H}$ & 21.6 & 40.8 & 37.2 & 6.0 & 23.4 & 64.0 \\
\hline & $P$ & 11.4 & 25.2 & 61.2 & 3.1 & 16.7 & 53.7 \\
\hline \multirow[t]{3}{*}{ Zhang Heping } & G & 20.0 & 36.7 & 40.0 & 10 & 23.3 & 26.7 \\
\hline & $\mathrm{H}$ & 15.2 & 27.2 & 48.5 & 9.1 & 27.3 & 24.2 \\
\hline & $P$ & 7.4 & 29.7 & 48.1 & 0.0 & 3.7 & 22.2 \\
\hline \multirow[t]{2}{*}{ Li Yongbin } & $\mathrm{G}+\mathrm{H}$ & 27.96 & 38.33 & 33.71 & 11.49 & 36.66 & 51.85 \\
\hline & $P$ & 31.66 & 43.93 & 24.41 & 20.27 & 44.48 & 35.25 \\
\hline \multirow[t]{2}{*}{ Fan Lihua } & $\mathrm{G}+\mathrm{H}$ & 21.2 & 33.6 & 45.4 & 18.9 & 32.0 & 49.1 \\
\hline & P & 9.6 & 69.8 & 20.6 & 32.9 & 50.7 & 16.4 \\
\hline \multirow[t]{2}{*}{ Yang Dehua } & $\mathrm{G}+\mathrm{H}$ & 20.7 & 33.6 & 30.2 & 10.0 & 22.5 & 58.0 \\
\hline & $P$ & 13.4 & 39.4 & 42.6 & 10.5 & 29.4 & 52.8 \\
\hline \multirow[t]{3}{*}{ Chen Jie } & $\mathrm{H} 1$ & 20.0 & 43.0 & 37.0 & 4.4 & 34.8 & 60.8 \\
\hline & $\mathrm{H} 2$ & 19.3 & 42.2 & 38.5 & 6.4 & 41.3 & 52.3 \\
\hline & $\mathrm{H} 3$ & 35.1 & 37.7 & 27.2 & 14.0 & 38.6 & 47.4 \\
\hline
\end{tabular}

Note: $G$ government managed $\mathrm{CHCs}, H$ hospital managed $\mathrm{CHCs}, P$ privately owned $\mathrm{CHCs}, \mathrm{H} 1$ primary hospital managed $\mathrm{CHCs}, \mathrm{H} 2$ secondary hospital managed $\mathrm{CHCs}, \mathrm{H} 3$ tertiary hospital managed $\mathrm{CHCs}$ 
national level and the study by Fan and colleagues [18] in Heilongjiang province found that the education level of health workers in privately owned $\mathrm{CHCs}$ was relatively higher than that in government managed and hospital managed CHCs. Among hospital managed $\mathrm{CHCs}$, the education level of health workers in tertiary hospital managed $\mathrm{CHCs}$ was higher than that in primary and secondary managed CHCs [24].

The health workforce in China is categorized into junior, middle and senior titles, which indicate their professional competency. The results regarding the differences in the professional titles of health workers among the three models of $\mathrm{CHCs}$ were inconsistent. Three studies in different places in China found that the professional titles of health workers in the privately owned $\mathrm{CHCs}$ were generally higher than in the government managed and hospital managed CHCs [18, 22, 25], while the study in Jiangsu province found that the professional titles of health workers in privately owned CHCs were the lowest among all three models of CHCs [23]. The study in Guangdong province found that the professional title of health workers in hospital managed $\mathrm{CHCs}$ was the highest among all three models of CHCs [21]. Furthermore, the professional title was found to be the highest for tertiary hospital managed $\mathrm{CHCs}$ among primary, secondary and tertiary hospital managed CHCs $[24,30]$.

\section{Primary care delivery}

Overall, six studies had focused on the delivery of primary care services $[13,19,21,22,24,26]$.

\section{Output of primary care}

Patients were more likely to seek health care services from hospital managed $\mathrm{CHCs}$ than the other two models of CHCs. Hospital managed CHCs were found to have better output of clinical care in terms of the average number of outpatient services per physician (i.e., the number of outpatient services that a physician offers) compared with $\mathrm{CHCs}$ of the other two models in Guangdong province [21]. The national study by $\mathrm{Xu}$ and colleagues [19] showed similar results. Additionally, among the $\mathrm{CHCs}$ operated by hospitals with different levels, tertiary hospital managed $\mathrm{CHCs}$ were the most preferred by patients. Chen and $\mathrm{Du}$ [24] showed that $76 \%$ of community residents in Beijing had ever used the primary care services of $\mathrm{CHCs}$ managed by tertiary hospitals, $61 \%$ had used the services of CHCs managed by secondary hospitals, and $58 \%$ had used the services of $\mathrm{CHCs}$ managed by primary hospitals.

Inconsistent results were found, when comparing the different models of $\mathrm{CHCs}$, with respect to the hypertension management rates, i.e., the proportion of hypertensive patients under the standard hypertension management out of the total number of hypertensive patients identified in the community. Two studies, one in Guangdong province and the other at the national level, showed that the hypertension management rate was the highest for the privately owned CHCs, followed by hospital managed $\mathrm{CHCs}$ and then government managed CHCs $[19,21]$. But another national study showed that the proportion was the lowest in privately owned CHCs [13]. In terms of health education, tertiary hospital managed $\mathrm{CHCs}$ were found to provide the best health education evaluated by patients compared to other hospital managed CHCs in Beijing [24]. Privately owned $\mathrm{CHCs}$ had the poorest vaccination rate in children when compared with government managed and hospital managed CHCs [19].

\section{Quality of care}

The quality of clinical and public health services provided by private $\mathrm{CHCs}$ tended to be poorer than that of the other two models of CHCs. For example, more irrational use of drugs defined by the number of drugs prescribed, percentage encounters with antibiotics prescribed, or percentage encounters with injections prescribed, had been observed among privately owned $\mathrm{CHCs}$ than the other models of CHCs [13]. Almost $95 \%$ of all $\mathrm{CHCs}$ had begun to establish health records for community residents, but the quality of health records (i.e., the completeness and accuracy) established by the hospital managed $\mathrm{CHCs}$ was better than that of the other two models of CHCs [19]. The quality of health records established by the privately owned $\mathrm{CHCs}$ was the poorest among the three models [13]. The studies reported inconsistent results using hypertension control rate as a quality indicator, i.e. the proportion of hypertensive patients whose blood pressure levels were under the target (i.e., 140/90 mmHg). One study [13] showed that the hypertension control rate was similar among the three models of CHCs, while the other study [21] showed that the hypertension control rate was the highest among privately owned $\mathrm{CHCs}$, followed by hospital managed $\mathrm{CHCs}$ and then government managed $\mathrm{CHCs}$. These conflicting results might be due to the underlying patient population mix.

\section{Public satisfaction}

The difference in public satisfaction regarding the primary care services provided by different models of CHCs was identified in six studies (Table 5). Four studies had shown that privately owned $\mathrm{CHCs}$ were more convenient than other models of CHCs [21, 26-28]. These studies also showed that more community residents were impressed by equipment in privately owned $\mathrm{CHCs}$ compared with the other two models of CHCs. Overall satisfaction was found to be the highest for government managed $\mathrm{CHCs}$ and the lowest for privately owned $\mathrm{CHCs}$ $[21,25,26]$. Community residents were more satisfied 
Table 5 Patient satisfaction ratings in proportions or scores

\begin{tabular}{|c|c|c|c|c|c|c|c|c|c|}
\hline First author & Comparison & Convenience & Environment & Equipment & Attitude & Price & Skill & Safety & Overall \\
\hline \multirow[t]{3}{*}{ Zhao Kun ${ }^{\text {a }}$} & G & 94.6 & 90.6 & 73 & 93.3 & 76.7 & 78.4 & 78.4 & 84.1 \\
\hline & $\mathrm{H}$ & 94.1 & 83.1 & 61 & 95.4 & 73.5 & 84.4 & 89.2 & 84.1 \\
\hline & $P$ & 95.8 & 88.7 & 74.6 & 90.2 & 67.6 & 73.3 & 70.5 & 80.6 \\
\hline \multirow[t]{3}{*}{ Yao Hongxia ${ }^{a}$} & G & 95.59 & 91.18 & 72.06 & 94.12 & 79.41 & 80.88 & 82.35 & - \\
\hline & $\mathrm{H}$ & 95.08 & 85.25 & 60.66 & 93.44 & 67.21 & 87.97 & 88.52 & - \\
\hline & $P$ & 96.92 & 92.31 & 78.46 & 92.31 & 72.31 & 76.92 & 73.85 & - \\
\hline \multirow[t]{2}{*}{ Wang Hongzhia } & $\mathrm{G}+\mathrm{H}$ & 90.0 & 78.25 & 61.24 & 88.64 & 69.14 & - & - & - \\
\hline & $P$ & 94.91 & 87.39 & 73.64 & 93.13 & 66.48 & - & - & - \\
\hline \multirow[t]{2}{*}{ Li Yongbin $^{a}$} & $\mathrm{G}+\mathrm{H}$ & - & - & - & - & - & - & - & 78.02 \\
\hline & $P$ & - & - & - & - & - & - & - & 72.71 \\
\hline \multirow[t]{3}{*}{ Guo Haixiu ${ }^{b}$} & G & 83.4 & 79.8 & 71.4 & 90.8 & 78.2 & 83.6 & - & 85.4 \\
\hline & $\mathrm{H}$ & 85.4 & 74.6 & 65.8 & 87.2 & 77.8 & 83.2 & - & 83.0 \\
\hline & P & 86.4 & 79.0 & 73.0 & 87.0 & 78.0 & 83.6 & - & 84.4 \\
\hline \multirow[t]{3}{*}{ Chen Jie ${ }^{b}$} & $\mathrm{H} 1$ & 4.08 & 4.03 & 3.40 & 4.14 & 4.13 & 3.75 & - & 3.99 \\
\hline & $\mathrm{H} 2$ & 4.16 & 3.44 & 3.02 & 4.26 & 4.12 & 4.10 & - & 4.04 \\
\hline & $\mathrm{H} 3$ & 4.46 & 3.98 & 3.48 & 4.27 & 3.95 & 4.20 & - & 4.22 \\
\hline
\end{tabular}

Note: $G$ government managed $\mathrm{CHCs}, \mathrm{H}$ hospital managed $\mathrm{CHCs}, \mathrm{P}$ privately owned $\mathrm{CHCs}, \mathrm{H} 1$ primary hospital managed $\mathrm{CHCs}, \mathrm{H} 2$ secondary hospital managed $\mathrm{CHCs}, \mathrm{H} 3$ tertiary hospital managed $\mathrm{CHCs}$

${ }^{a}$ in proportions

bin scores

with the price of health services and drugs provided by government managed $\mathrm{CHCs}$ than that of the other models of $\mathrm{CHCs}$, while they were more satisfied with the clinical services provided by hospital managed $\mathrm{CHCs}$ than other models [26, 27]. No conclusion could be drawn in terms of patient satisfaction regarding hospital environment and the attitude of health workers across the three models of CHCs. Patients were more satisfied with tertiary hospital managed $\mathrm{CHCs}$ compared with $\mathrm{CHCs}$ managed by smaller hospitals [29].

\section{Discussion}

This systematic review has retrieved and synthesized papers comparing the three models of $\mathrm{CHCs}$, the main providers of primary care services in China. Even though a large number of studies of CHCs have emerged since 1997, studies that have given definite descriptions of the models of $\mathrm{CHCs}$ are relatively limited, and thus only 13 papers were included in this review. Privately owned $\mathrm{CHCs}$ were found to have the smallest workforce in healthcare, the lowest share of government funding against the total revenue, the highest share of out-ofpocket payments, and the lowest coverage rate of health insurance schemes. There was a general trend that the quality of primary care services provided by privately owned $\mathrm{CHCs}$ was the poorest among the three models of CHCs. Healthcare workers of privately owned CHCs received fewer training opportunities than the other two models of CHCs. Community residents tended to use more services from hospital managed CHCs, especially the tertiary hospital managed ones. Patients were mostly satisfied with privately owned $\mathrm{CHCs}$ as regards the convenience of their services and the medical equipments provided, while patients were more satisfied with the better health services provided by hospital managed CHCs.

\section{Limitations of the study}

The present systematic review provides a summary of the differences among the three major models of CHCs in China, which may allow policy makers to develop strategies on health care resources allocation and care supervision. However, some limitations should be mentioned hereby. Firstly, this systematic review only included a small number of studies. The robustness of the current findings might be limited. For one thing, selection bias might have been introduced as only papers in English or Chinese were retrieved, though we believe this may cover most of studies on this topic. For another, inclusion bias might exist because most studies were excluded after reviewing titles and abstracts but not through full-text reviewing, which might have limited the generalizability of the study findings. A second limitation may relate to the methodological quality of included studies. Three studies employed purposive sampling method to select $\mathrm{CHCs}$ which might have introduced sampling bias although we considered this sampling strategy to be relevant to the objectives of the studies. Of the six studies with respect to patient satisfaction, few have 
reported the validity and reliability of the measures employed, although the measures were widely recognized to be effective in assessing patient satisfaction. Additionally, they reported little consideration of confounding variables, limiting internal validity of the studies. Finally, the functions of $\mathrm{CHCs}$ in different local contexts such as financing approach and human resources were subject to the local implementation of primary care, e.g., regulations. Overall, caution should be made when interpreting the findings.

\section{Possible explanations for the main findings}

All $\mathrm{CHCs}$ faced a serious shortage of trained health workers in China [31]. The average education level of the health workers remained relatively low, possibly because most graduates with higher education level tended to join large-scale hospitals. Primary care organizations tended to have a healthcare workforce with poor academic backgrounds, insufficient practice guidelines, and unclear responsibilities compared to hospitals [32]. Private $\mathrm{CHCs}$ were less competitive compared with other $\mathrm{CHCs}$ as public organizations, which have better job security and welfare benefits in China. Therefore, privately owned $\mathrm{CHCs}$ were found to have the smallest number of health workers, who had received the least training opportunities, which is possibly because of financial constraints and the profit-driven objectives of the privately owned CHCs.

Primary care was inadequately funded by the government even though it had been set out as the foundation of the new comprehensive reform plan in China [33]. Privately owned $\mathrm{CHCs}$ were the least well funded due to their ownership status, in spite of the increased payments to $\mathrm{CHCs}$ for public health services provision in recent years [12]. Without sufficient government funding, $\mathrm{CHCs}$ did not have the motivation to provide public health services that do not generate economic returns [34]. Thus, $\mathrm{CHCs}$, especially the private ones, may focus more on providing clinical care than public health services.

Health insurance schemes have become a larger payer of the primary care services provided in $\mathrm{CHCs}$ due to the rapid expansion of the Basic Medical Insurance Scheme for Urban Employees and Basic Medical Insurance Scheme for Urban Residents, which together covered a total of over $80 \%$ of the urban population in China as of the end of 2008 [35]. It was more likely for private $\mathrm{CHCs}$ to be left out by public health insurance schemes due to their ownership status. The elders and migrants, the two vulnerable groups in the community, tended to visit $\mathrm{CHCs}$ due to their low price and convenience [36], but these groups of users were more likely to be uninsured [37]. Lower insurance coverage usually results in lower use of essential health services among the elders [38] and migrants [39], which may jeopardize the goal of equity in primary care services' provision. This also explains the observation why out-of-pocket payments consisted of the largest proportion of total revenues in CHCs.

This review has shown that the quality of community health services was more likely to be poor at the privately owned $\mathrm{CHCs}$. This finding is in line with the studies from other countries that quality of care is usually worse in privately owned health facilities when compared with that of publicly financed ones [40-43]. Human resources are widely recognized to be associated with the quality of community health services [44]. However, in our study, the difference in the capacity of the health workers (i.e., education level and professional title) among the three models of $\mathrm{CHCs}$ was not consistent. Poor financial investment is one of the most significant impediments to the delivery of primary care services and contributes to poor quality of care [45]. Thus, insufficient investment from the government for the provision of public health services may be an important reason for the poor quality of public health services offered by privately owned CHCs. Additionally, the profit seeking nature of privately owned $\mathrm{CHCs}$ is another possible reason of lower quality of care provided by these $\mathrm{CHCs}$, as they are more likely to prescribe drugs to patients to make profits.

It has been observed that people tended to use community health services provided by hospital managed $\mathrm{CHCs}$, especially the tertiary hospital managed ones. This reflects the better reputation of hospitals, especially big hospitals, regarding quality of health care [46]. Higher satisfaction with clinical services may also contribute to the higher utilization rate of primary care services offered by hospital managed CHCs. Moreover, the greater awareness of community health services provided by the hospital managed $\mathrm{CHCs}$ in the community may be another possible reason for the better utilization of hospital managed CHCs [29].

Privately owned CHCs had the lowest overall satisfaction ratings, which may possibly due to the perceived poor quality of health services, as with similar results found in other countries [47]. Private CHCs tend to compete with public ones on the convenience of services (i.e., opening hours and locations), the medical equipment and the appearance of offices [48].

\section{Policy implications}

This systematic review provides comprehensive evidence to policy makers for the future development of health policies for better primary care system development in China. In response to health personnel shortage and their limited capacity, the State Council of the Central Government has enacted a plan with specific strategies in training both new graduates and the current health 
workforce. In addition, other policies should be targeted at better professional recognition and higher salaries through government funding. The capitation payments can encourage $\mathrm{CHC}$ doctors to provide care of good quality [49]. Special attention should be given to privately owned $\mathrm{CHCs}$ as international evidence has shown that private organizations are less likely to provide training for their employees [50-51]. Doctors in private $\mathrm{CHCs}$ are likely to have better capacity in primary care if the government purchases public health care services as it does from public ones. Health insurance schemes should cover private $\mathrm{CHCs}$ as well as public ones to ensure better financial access to primary care services [52], as vulnerable populations such as the elderly and migrants tend to use $\mathrm{CHC}$ services.

Research gaps have been identified regarding the performance of different primary care delivery models. Quality improvement is the central focus of health care [53]. Recent studies suggested a possible association between quality of care and organizational factors among primary care providers [54, 55]. CHCs of different models in China have different financing approaches, numbers in their health workforce, as well as premises; we speculate that these differences may translate into differences in the quality of primary care services supplied. However, a few studies compared the quality of care delivery processes using indicators such as the appropriateness of medication prescriptions, the completeness of health records and vaccination rates, all of which were from a health professional's perspective. Few explored the quality of care delivery processes from a patient's perspective for performance comparison among CHCs. No such studies developed a comprehensive framework for such a performance comparison among different models of $\mathrm{CHCs}$, rendering it difficult to characterize how well each model performs across the dimensions of primary care (i.e., structure, process and outcome) and make it difficult to provide strategic recommendations for the long-term development of primary care.

\section{Conclusions}

In summary, government and hospital managed $\mathrm{CHCs}$ in China were more competent and tended to provide primary care services with higher quality than privately owned CHCs. More studies are warranted to comprehensively address the performances of different models of CHCs.

\section{Competing interests}

The authors declare that there are no competing interests.

\section{Authors' contributions}

XLW and SG conceived of the study. HTL, DFQ and RC participated in the literature search and drafted the manuscript. HTL, RC and XLW are responsible for data analysis and interpretation. SG and DFQ revised the draft for intellectual content. All authors read and approved the final manuscript.

\section{Acknowledgements}

This work was supported by the Research Grants Council (RGC) of Hong Kong (CUHK 4002-SPPR-10), and the National Natural Science Fund of China (71173118). However, the funders had no roles in study design, data collection and interpretation, writing and submission of the manuscript. The authors would like to thank Nan Yang and Hui Xia for their assistance in data abstraction.

\section{Author details}

${ }^{1}$ School of Medicine, Shenzhen University, Shenzhen, China. ${ }^{2}$ School of Health Policy and Management, Nanjing Medical University, Nanjing, China. ${ }^{3}$ School of Public Health and Primary Care, Faculty of Medicine, The Chinese University of Hong Kong, Hong Kong, China. ${ }^{4}$ Dalla Lana School of Public Health, University of Toronto, Toronto, Canada.

Received: 30 December 2014 Accepted: 30 October 2015

Published online: 10 November 2015

\section{References}

1. Hu S, Tang S, Liu Y, Zhao Y, Escobar ML, de Ferranti D. Reform of how health care is paid for in China: challenges and opportunities. Lancet. 2008;372(9652):1846-53.

2. Tang S, Meng Q, Chen L, Bekedam H, Evans T, Whitehead M. Tackling the challenges to health equity in China. Lancet. 2008;372(9648):1493-501.

3. Yip W, Mahal A. The health care systems of China and India: performance and future challenges. Health Aff (Millwood). 2008;27(4):921-32.

4. Casanova C, Starfield B. Hospitalizations of children and access to primary care: a cross-national comparison. Int J Health Serv. 1995;25(2):283-94.

5. Macinko J, Starfield B, Shi L. The contribution of primary care systems to health outcomes within Organization for Economic Cooperation and Development (OECD) countries, 1970-1998. Health Serv Res. 2003;38(3):831-65.

6. Saltman RB, Rico A, Boerma WG. Primary care in the driver's seat? Organizational reform in European primary care. Maidenhead,UK: Open University Press.

7. Shi L, Starfield B. Primary care, income inequality, and self-rated health in the United States: a mixed-level analysis. Int J Health Serv. 2000;30(3):541-55.

8. Shi L, Starfield B, Kennedy B, Kawachi I. Income inequality, primary care, and health indicators. J Fam Pract. 1999;48(4):275-84.

9. Schoen C, Osborn R, Huynh PT, Doty M, Davis K, Zapert K, et al. Primary care and health system performance: adults' experiences in five countries. Health Aff. 2004;Suppl Web Exclusives:W4-487-503.

10. The State Council of the People's Republic of China. The suggestions of deepening reform of public health and medicine undertaking. 2009.

11. Ministry of Health. Chinese health statistics in 2009. 2009.

12. Ministry of Health. Chinese health statistics in 2010. 2010.

13. Wang Y. Study on characteristics and development tactics of community health service institutions by different holders. Wuhan, China: Huazhong Technology University; 2008.

14. Hsiao W. What is a health system? why should we care? 2003.

15. Pace R, Pluye P, Bartlett G, Macaulay AC, Salsberg J, Jagosh J, et al. Testing the reliability and efficiency of the pilot Mixed Methods Appraisal Tool (MMAT) for systematic mixed studies review. Int J Nurs Stud. 2012;49(1):47-53.

16. Pluye P, Gagnon MP, Griffiths F, Johnson-Lafleur J. A scoring system for appraising mixed methods research, and concomitantly appraising qualitative, quantitative and mixed methods primary studies in Mixed Studies Reviews. Int J Nurs Stud. 2009;46(4):529-46.

17. Squires JE, Hutchinson AM, Bostrom AM, O'Rourke HM, Cobban SJ, Estabrooks CA. To what extent do nurses use research in clinical practice? A systematic review. Implement Sci. 2011;6:21.

18. Fan L, Hu H, Li L, Sun T. SWOT analysis of different ownership of CHCs. Chinese Rural Health Service Administration. 2007;27(2):107-9.

19. Xu Z, Zhen $X$, Yao L. Comparative analysis of the status quo of the function of community health service institutions held by different sponsors. Chinese Health Economics. 2011;30(7):84-6.

20. Hou W, Li Y, Wang F, Lu Z. Progress of medical insurance in community health facilities of the key contact cities. Chinese J Health Policy. 2010;3(2):17-20.

21. Guo H. A comparison study on three kinds of community health service models in Guangdong province. Guangzhou, China: Zhongshan University; 2010.

22. Yang D, Dai G. Research on service to community health service centers by different holders in Chengdu city. Chinese Health Economics. 2010;29(6):62-4. 
23. Zhang $\mathrm{H}$. Comparative research on the urban community health service model of Jiangsu province. Suzhou, China: Suzhou University; 2008.

24. Chen J, Du X. Present status of health education conducted by community health service institutions from different leveld hospitals. Chinese General Practice. 2010;13(9A):2794-7.

25. Li Y, Cao S, Wang F, Lu Z. The SWOT analysis of community health service by different holders in key contact cities. Chinese J Soc Med. 2010;27(4):224-6.

26. Zhao K, Zhang Y, Yao H. Comparative analysis on service delivery of comunity health service institutions of different ownerships. Chinese General Practice. 2010;13(8A):2430-2.

27. Yao $H$, Zhao $K$, Zhang $Y$, Wu $H$. Investigation of residents' satisfaction on community health service institutions held by different ownership. Chinese General Practice. 2010;13(7A):2081-3.

28. Wang Z, Wang Y, Wang F, Lu Z. Analysis on satisfaction to community health service institutions by different holders. Chinese General Practice. 2009;12(1A):75-6.

29. Chen J, Du X, Xi X. Analysis on satisfaction of residents to community health service held by different level medical institutions. Chinese General Practice. 2009;12(8):1443-5.

30. Li F. Advantages and disadvantages of hospital managed community health services. Chinese Health Management. 2009;(9):592-4.

31. Yip W, Hsiao W, Chen W, Hu S, Ma J, Mayard A. Early appraisal of China's huge and complex healthcare reforms. Lancet. 2012;379:833-42.

32. Dib H, Sun P, Minmin Z, Wei S, Li L. Evaluating community health centers in the city of Dalian, China: how satisfied are patients with the medical services provided and their health professionals? Health Place. 2010;16(3):477-88.

33. Bhattacharyya O, Delu Y, Wong ST, Bowen C. Evolution of primary care in China 1997-2009. Health Policy. 2011;100(2-3):174-80.

34. Zhang L, Yi C, Gong X, Bing R. The private community health system situation and some suggestions in Wuhan. Chinese Health Economics. 2007;26(6):36-8.

35. Barber SL, Yao L. Development and status of health insurance systems in China. Int J Health Plann Magmt. 2011;26:339-56.

36. Wei X, Pearson S, Zhang Z, Qin J, Gerein N, Walley J. Comparing knowledge and use of health services of migrants from rural and urban areas in Kunming City, China. J Biosoc Sci. 2010;42(6):743-56.

37. Yang $Y$, Yang D. Community health services centers in China, not always trusted by the populations they serve? China Econ Rev. 2009;20:620-4.

38. Wei $X$, Zakus D, Liang $H$, Sun $X$. The Shanghai Case: a qualitative evaluation of community health reform in response to the challenge of population aging. Int J Health Plann Manag. 2005;20(3):269-86.

39. Mou J, Cheng J, Zhang D, Jiang H, Lin L, Griffiths SM. Health care utilisation amongst Shenzhen migrant workers: does being insured make a difference? BMC Health Serv Res. 2009;9:214.

40. Crabtree B, Miller W, Tallia A, Cohen D, DiCicco-Bloom B, Mcilvain H. Delivery of clinical preventive services in family medicine offices. Ann Fam Med. 2005;3:430-5.

41. Stange K, Flocke S, Goodwin M, Kelly R, Zvzanski S. Direct observation of rates of preventive service delivery in community family practice. Prev Med. 2000;31:167-76.

42. Wei X, Yang N, Gao Y, Wong SY, Wong MC, Wang J, et al. Comparison of three models of ownership of community health centres in China: a qualitative study. J Health Serv Res Policy. 2015;20(3):162-9.

43. Wei X, Li H, Yang N, Wong SY, Owolabi O, Xu J, et al. Comparing quality of public primary care between Hong Kong and Shanghai using validated patient assessment tools. PLoS One. 2015;10(3):e0121269.

44. Qian D, Lucas H, Chen J, Xu L, Zhang Y. Determinants of the use of different types of health care provider in urban China: a tracer illness study of URTI. Health Policy. 2010;98:227-35.

45. Nelson BD, Simic S, Beste L, Vukovic D, Bjegovic V, VanRooyen MJ. Multimodal assessment of the primary healthcare system of Serbia: a model for evaluating post-conflict health systems. Prehosp Disaster Med. 2003;18(1):6-13.

46. Liu Q, Wang B, Kong Y, Cheng K. China's primary health care reform. Lancet. 2011;377:2064-6.

47. Stevens PE, Farmer CK, de Lusignan S. Effect of pay for performance on hypertension in the United Kingdom. Am J Kidney Dis. 2011;58(4):508-11.

48. Chi Y, Yao L, Zhang L. Advantages and challenges of provate CHS. Chinese Health Economics. 2007:26(12):10-2
49. Wei X, Li H, Yang N, Wong SYS, Chong MCS, Shi L, et al. Changes in the perceived quality of primary care in Shanghai and Shenzhen, China: a difference-in-difference analysis. Bull World Health Organ. 2015;93:407-16.

50. Propper C. The demand for private health care in the UK. J Health Econ. 2000;19(6):855-76.

51. Mills R, Brugha K, Hanson, McPake B. What can be done about the private health sector in low-income countries? Bull World Health Organ. 2002;80:325-30.

52. Li H, Wei X, Wong MC, Yang N, Wong SY, Lao X, et al. A comparison of the quality of hypertension management in primary care between Shanghai and Shenzhen: a cohort study of 3196 patients. Medicine. 2015:94(5):e455.

53. Campbell S, Braspenning J, Hutchinson A, Marshall M. Research methods used in developing and applying quality indicators in primary care. Qual Saf Health Care. 2002;11(4):358-64.

54. Cretin S, Shortell SM, Keeler EB. An evaluation of collaborative interventions to improve chronic illness care. Framework and study design. Eval Rev. 2004;28(1):28-51.

55. Stevenson K, Baker R, Farooqi A, Sorrie R, Khunti K. Features of primary health care teams associated with successful quality improvement of diabetes care: a qualitative study. Fam Pract. 2001;18(1):21-6.

\section{Submit your next manuscript to BioMed Central and take full advantage of:}

- Convenient online submission

- Thorough peer review

- No space constraints or color figure charges

- Immediate publication on acceptance

- Inclusion in PubMed, CAS, Scopus and Google Scholar

- Research which is freely available for redistribution

Submit your manuscript at www.biomedcentral.com/submit 